\title{
IMPACT OF THE PORT STRUCTURE IN THE SPATIO-TEMPORAL EVOLUTION OF THE SEDIMENTARY AND BATHYMETRIC CHARACTERISTICS OF A MOROCCAN ATLANTIC BAY, STUDY CASE BAY OF SAFI CITY
}

\author{
A. Minoubi ${ }^{1,2}$, M. Bouchkara ${ }^{2 *}$, K. El Khalidi ${ }^{2}$, M. Chaibi ${ }^{3}$, M. Ayt Ougougdal ${ }^{3}$ and B. Zourarah ${ }^{2}$ \\ ${ }^{1}$ Interdisciplinary Laboratory LIRBEM, Department of Life and Earth Sciences, Ecole Normale Supérieure, Cadi Ayyad \\ University, Marrakech, Morocco \\ ${ }^{2}$ Associated Unit URAC 45, Marine Geosciences and Sol Sciences Laboratory, Department of Geology, Faculty of Sciences, \\ University Chouaib Doukkali, El Jadida B.P. 20, 2400, Morocco \\ ${ }^{3}$ Physical Geography Laboratory, Cadi Ayyad University, Polydisciplinary Faculty, Department of Natural Sciences and \\ Geography, Safi, Morocco
}

Commission 4, WG 7

KEYWORDS: Safi Bay, morpho-sedimentary, development, port, lowering, raising

\begin{abstract}
This study focuses on morpho-sedimentary changes in the bay of Safi (Atlantic coast of Morocco), due to a progressive extension of the port. For this purpose, several bathymetric and sedimentary surveys carried out by the Hydrographic and Oceanographic Service of the Navy (SHOM) in 1892, 1906 and 1940 respectively, coupled with a bathymetric and sedimentary measurement mission in 2009, were analyzed to understand the impact of the port developments on the bottom of Safi Bay. This analysis consists of making maps of the evolution of (i) sedimentary facies (of different dates 1892, 1906, 1940 and 2009) and (ii) the shallow seabed of the three periods 1892-1906, 1906-1940 and 1940-2009. The sedimentary facies maps show that the facies appear unstable and evolve intermittently in response to environmental changes in the bay (port construction and expansion). In addition, the overlay of the bathymetric maps indicates that the bay has undergone changes (lowering, stability, and raising) controlled by hydrodynamic conditions before, during, and even after harbor construction. Analysis of the data showed that the expansion of the port often reshaped the morphology of the bay's seabed. The consequences of these evolutions are the appearance of the fattening or the erosion of the bank and the filling of small depressions of sediments. This evolution is reflected in the modification of the funds near the port and the beach of Safi
\end{abstract}

\section{INTRODUCTION}

The coastal sediment transport volumes are disturbed by human interventions in coastal environments. These sedimentary changes destabilize the coastline and alter the nearshore sediment budget (Dubois, 2000; El Khalidi et al., 2012; Minoubi et al., 2018; Paskoff, 1998; Samat et al., 2007). Human interventions in the coastal zone (source of sediments) have altered the natural balance in the world, concerning the amount of sediment and its transport mode (Stanica et al., 2007). Human developments, especially harbors, are the cause of the hydrodynamic disturbance, generally translated by morphological changes (lowering/raising).

The construction of a harbor results in changes in the sedimentary facies of the bottom (Martin et al., 2012) and it also contributes to an intensive local change in the geometry and topography of the coastal environment (W. Guo et al 2017). Harbor jetties have changed the morphology of beaches (FlorBlanco et al., 2015; Henrico and Bezuidenhout, 2020). These development structures influence wave refraction/diffraction dynamics (Flor-Blanco et al., 2015) and tidal characteristics (W. Guo et al 2017) by causing changes in coastal systems (Henrico and Bezuidenhout, 2020). They interrupt longshore drift and block sediment at the upstream drift, promoting beach growth caused by wave refraction (Flor-Blanco et al., 2015; Minoubi et al., 2018).

Numerous developments (especially port facilities) have been carried out on the Moroccan coasts are materialized by significant modifications in the shallow sea (Charrouf, 1991).
The large bay of Safi has undergone several imbalances due to the important modifications made to its natural regime. It is of socio-economic interest to the city. Very early on, since 1906, this bay was artificialized by the construction of the port, which began in 1906 and was completed in 1986. Because of its opening on the dominant swells of North to North-West direction with a dominant sedimentary transit directed North-South, this port played very quickly a role of sediment trap. Thus, this anthropogenic development interacts with the coastal environment, contributes to the change of beach morphology (Minoubi et al., 2018), and modifies the sediment cover of the bottom of the Safi Bay. These changes result, among other things, in the clogging of the navigation channel, which requires annual dredging of an estimated $150,000 \mathrm{~m}^{3}$ of sand and silt (Charrouf, 1991) to maintain access. Ports' built-in bays regularly suffer from silting of their basins. This siltation of the harbors, therefore, requires continuous dredging to ensure the safety of the shipping lanes (Henrico and Bezuidenhout, 2020). The deposition of alluvium in these bays is often the main cause of changes in its bathymetry (Henrico and Bezuidenhout, 2020). These port facilities have positive consequences since they have contributed to the establishment of a beach of great tourist importance at the local level since initially, the coastline of this region is dominated by cliffs (Minoubi et al., 2018). On the other hand, these morpho-sedimentary changes at the bottom of the bay played a negative role, materialized by the confinement and sedimentary clogging of the navigation channel (Charrouf, 1991). 
The present study aims to analyze the evolution of sedimentary fractions and the morphology of the bottom before, during, and even after the major developments of the bay of Safi. To this end, bathymetric surveys and sediment samples of different date scales covering the period from 1892 to 2009 were used to assess the historical evolution of the bay of Safi in terms of morphosedimentary changes, taking into account the impact of port developments on the morphology of this bay.

\section{MARTIALS AND METHODS}

\subsection{Study site.}

The bay of Safi is limited by the point of Toure (Sidi Bouzid) to the north and the point of Rouazi (Jorf Ammouni) to the south (Figure 1). It is drawn between these two points by the retreat of the Quaternary land, which puts this bay sheltered from the NW swells. This bay extends over a coastal line that includes the beach of Sidi Bouzid to the north of the port and the sharp cliff to the south of the port. The diachronic analysis of this coastal linear shows that its northern part has known an advance while its southern part is characterized by erosion (Minoubi et al., 2018).

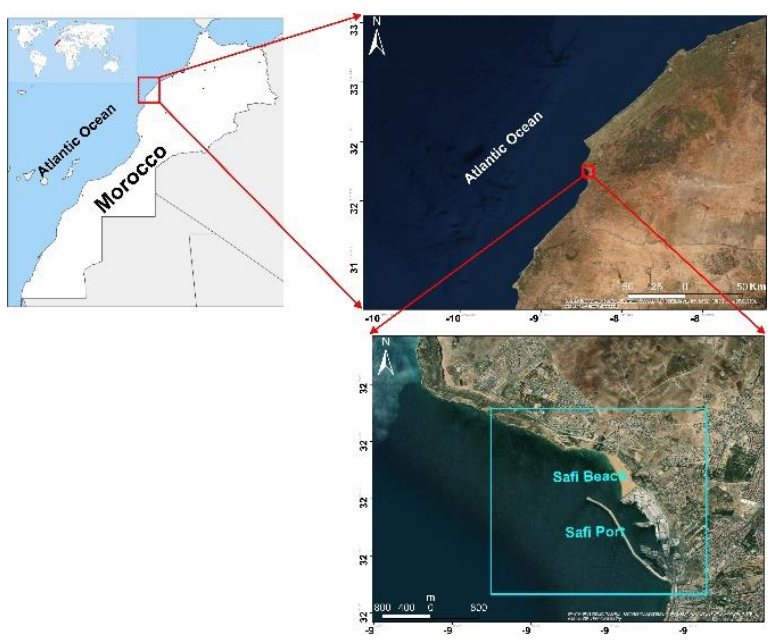

Figure 1. Location of the study area

The wind regime is variable during the year (according to the SHOM mission, 1948), the most frequent are generally from NE and $\mathrm{E}$ with low to moderate speed. Strong to stronger winds are mainly from $\mathrm{W}$ and SW. According to the data obtained in situ by the SHOM from October to May 1949, the swell regime is classified into three categories (i) storm swells from the SW sector, gales, having an erosive effect on the coast, ii) storm swells from the NW sector, having an erosive effect on the (ii) strong swells of NW - W direction with an amplitude greater than three meters before breaking, (iii) weak and medium swells from NW to $\mathrm{W}$ with an amplitude less than two meters.

The statistical distribution of significant wave heights from NOA, for the period 1997-2009, including 2568 days, show that $58 \%$ of the swells have a significant height (HS) between 1.25 and $2.5 \mathrm{~m}$. Low (0.5-1.25) and medium (2.5-4) swells (2.5-4) represent respectively $15.29 \%$ on 175 days and $21.1 \%$ on 212 days, while $5 \%$ of the strong swells between 4 and $9 \mathrm{~m}$ of Hs. The comparative study of swell direction and height (Hs) shows that the dominant frequencies $(\mathrm{NW})$ are associated with higher Hs, then decrease proportionally with frequency. On the other hand, the strongest swells, called exceptional (storms), coincide with a SW orientation. They represent less than $2 \%$ of cases.
Under the effect of the oblique origin of the swell at the coast (the littoral drift), the sands move from north to south. The value of this littoral transit is estimated at $250,000 \mathrm{~m} 3 /$ year, most of which occurs during storm days (Charrouf, 1991).

\subsection{Bathymetric data collection and analysis}

Numerous bathymetric surveys and superficial sediment samples were carried out in the roadstead of Safi during the years 1892, 1906 and 1940, by the Hydrographic and Oceanographic Service of the Navy (SHOM) of Brest where I was able to consult the original maps. The bathymetric minutes are more precise documents presented as minutes of writing of probe where appear at the same time the depths of water and the nature of the funds obtained by the method of the suiffé lead. Their digitization was made on the RETINE software developed by the SHOM.

This work consisted, first, in digitizing the bathymetric records and georeferencing them in Lambert Nord Maroc coordinates system. The spatial distribution of bathymetric soundings carried out by SHOM gives a high density of radial measurements. The number of bathymetric soundings is variable from one survey to another. The 1892 bathymetric chart has 464 sounding points, while the 1906 bathymetric survey has 1127 sounding points and the 1940 bathymetric survey has 1031 sounding points spread over the whole bay of Safi. To update the previous bathymetric and sedimentary data, a bathymetric field mission was organized in 2009. During this mission, the data were recorded with a bathymetric sounder coupled to a differential G.P.S. while the sediments were collected by a van Veen grab. 1026 sounding points were surveyed.

In order to have a basis for comparison, bathymetric data for the offshore area of Safi Bay were provided for the years 1892, 1906, 1940 and 2009. Bathymetric data analysis and map production were carried out in ArcMap (ArcGIS9.0), using a kriging interpolation method (Curtarelli et al., 2015) and geotechnical analyst technique for validation. Grids of equally scaled data points were interpolated to produce calculated surfaces. Surfaces were overlaid or subtracted to evaluate depth changes. Calculation of deposited and extracted material volumes was performed using the Cutfill tool in GIS software. The Cutfill is a technique in which the surface height changed by the process of removal/addition of surface materials. It provides a summary of the areas and volumes changed between 1892 and 1906; 1906 and 1940; 1940 and 2009, respectively, by identifying areas where surface materials have been removed or added, as well as areas where the surface has not been changed. The results are obtained in the form of a map that defines the sedimentary state of the study area with a table calculating the different volumes and surfaces identified.

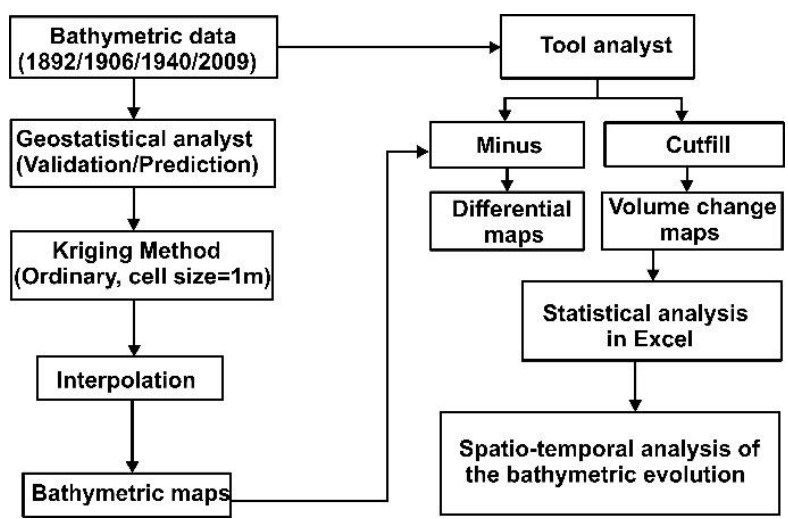

Figure 2. Flowchart of bathymetric study of Safi Bay. 


\section{RESULTS AND DISCUSSIONS}

\subsection{Morphosedimentary changes}

The 1892 sounding map shows that the sandy facies dominate and cover more than $70 \%$ of the bottom, while the muddy facies, which are not well represented, are confined to a few adjacent points, and muddy sands are annotated in the central area of the bay.

At that time, the bay of Safi was still wild and tidal currents did not flow along the bottom from the $-30 \mathrm{~m}$ isobath (Charrouf, 1991). In this area, the facies are mainly muddy and their distribution is oriented along the general slope towards the open sea. It should be noted that this facies extends towards the coast up to the $-20 \mathrm{~m}$ isobath, and particularly in the center of the bay (Figure 3). While rocky areas exist locally and form a band parallel to the coast around the $-10 \mathrm{~m}$ isobath.

The unpublished 1906 sounding record has more than 1000 annotations of stuffed lead. Contrary to the sedimentological state of the bay in 1892, we note the presence of zones of gravel and shells (breccias) beyond the $-30 \mathrm{~m}$ isobath. This high granulometry marks the action of strong bottom currents that carry these materials away. The areas of sandy sedimentation have spread widely over the whole of Safi Bay (figure 3). Muddy sands and sandy muds are distributed in fairly limited areas. The very small rocky areas, mostly limited to small corridors, are scattered in the south of the bay under a shallow water depth $(0$ and $10 \mathrm{~m}$ ). This change in facies during this period (1892-1906) indicates that the marine hydrodynamic of the Safi Bay is unstable. The shallows are remodeled by medium and fairweather swells, while sedimentary inputs are made only during a few days of storms (Charrouf, 1991). At that time, the bay of Safi was still undeveloped, which explains that this moderate change in the granulometry of sediments was related to the forcing agents of the environment.

The 1940 map shows the same geographic break as the 1906 map. The distribution of sedimentary facies is quite similar to that observed in 1906 . Over the entire bay, the bottom is mostly sand. The muddy cover is still limited to the south, but unlike the 1906 map, there are some silted patches in a predominantly sandy environment. Gravel facies to the west and southeast of the bay with small scattered channels in the sandy facies (Figure 3 ). The port of Safi began its expansion from the year 1908. This port is open to the north-south coastal transit, it stops almost all the coastal transit and works as a sediment trap. This intervention had modified the marine hydrodynamics and causes an accumulation from the coast to the open sea.

The coastal transit, trapped by the port, estimated at 250,000 $\mathrm{m} 3$ occurs in a coastal strip between the zero isobath and -8 meters. The blockage of sediments in this band contributes to the feeding of the shallow waters and leads to the change of facies during this period.

In contrast to the maps published in 1892,1906 , and 1940 , the changes in facies boundaries are very significant since 1940 . facies appear very important since 1940. Sands dominate and muddy or sandy-muddy sediments only represent 15 to $20 \%$ of the marine sediments in this bay. Muddy sediments are reduced to a few silted patches in an environment sandy environment ( $\mathrm{J}$, 1951). Contrary to the state of the bay in 1940, two small corridors of mud appear to the north of the bay (Figure 3). In addition, rocky areas are observed at shallow depths on the south coast.

The four maps cover the evolution of the sedimentary facies' distribution in Safi Bay over 116 years. The last two maps, those of 1906 and 1940, show little change in sedimentary facies boundaries and bathymetry. On the other hand, the comparison of the old maps $(1892,1906$, and 1940) with the 2009 map shows changes in both the nature and depth of the seabed. Since 1940, it can be noted that the funds near the beach of Safi and the channel of the port have silted up in 2009.

\subsection{Bathymetric evolution of the shallow waters of Safi Bay}

The period 1892-1906 shows that the bay of Safi has experienced bathymetric variations (Figure 4). This evolution is reflected by an exhaussement in the northern part of the bay, in contrast, the median and southern part materialized by a generalized erosion (figure). The volume of sediment deposited in the northern part of the harbor was $17710981.969 \mathrm{~m}^{3}$ calculated on an area of $5744619 \mathrm{~m}^{2}$. In the southern part, the volume lost was $3662609.403 \mathrm{~m}^{3}$ over an area of $1653741 \mathrm{~m}^{2}$ for a depth up to $30 \mathrm{~m}$. The accretion of the northern zone is the origin of the sedimentary contributions transited on the coastal strip from zero to -8-meter depth (Charrouf, 1991). The bathymetry of the bay of Safi before the construction of the port (period 1892-1906) was therefore influenced only by natural factors of tides and swell action. The northern part of the bay is sheltered from the incidence of dominant swells coming from the NW. This aspect is at the origin of the decrease in hydrodynamic energy and the deposition of sediments. The change of the central and southern zone of the bay indicates that the bottoms between 10 and $30 \mathrm{~m}$ deep are less fed by sediment transit and seem more influenced by bottom currents. The openness of the bay to the prevailing NW-SE swells and the exposure of its southern shoreline also favors the process of erosion by hydrodynamic forcing agents. 
The International Archives of the Photogrammetry, Remote Sensing and Spatial Information Sciences, Volume XLVI-4/W3-2021 Joint International Conference Geospatial Asia-Europe 2021 and GeoAdvances 2021, 5-6 October 2021, online
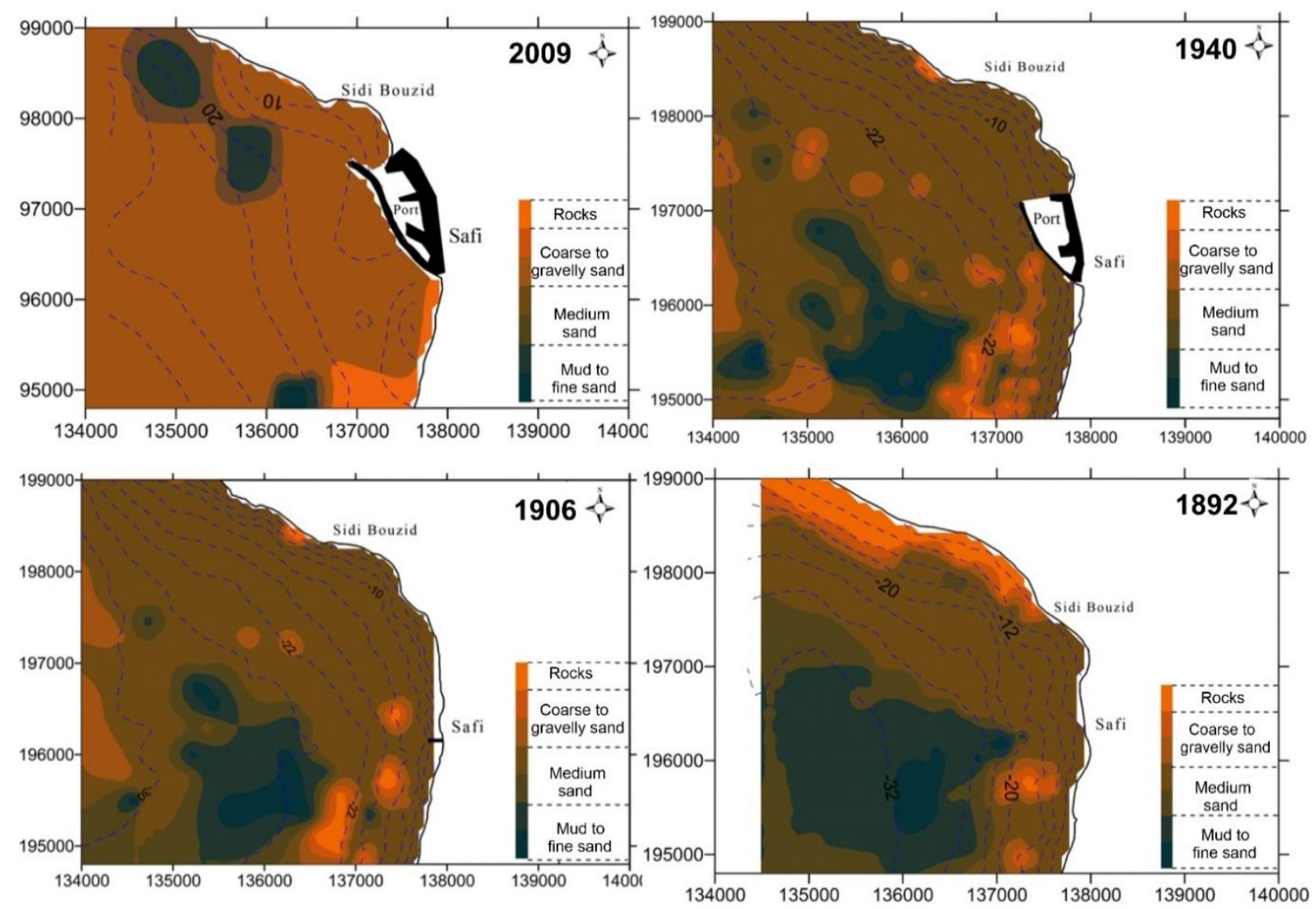

Figure 3. Distribution of sedimentary facies in Safi Bay in 1892, 1906, 1940 and 2009, respectively.
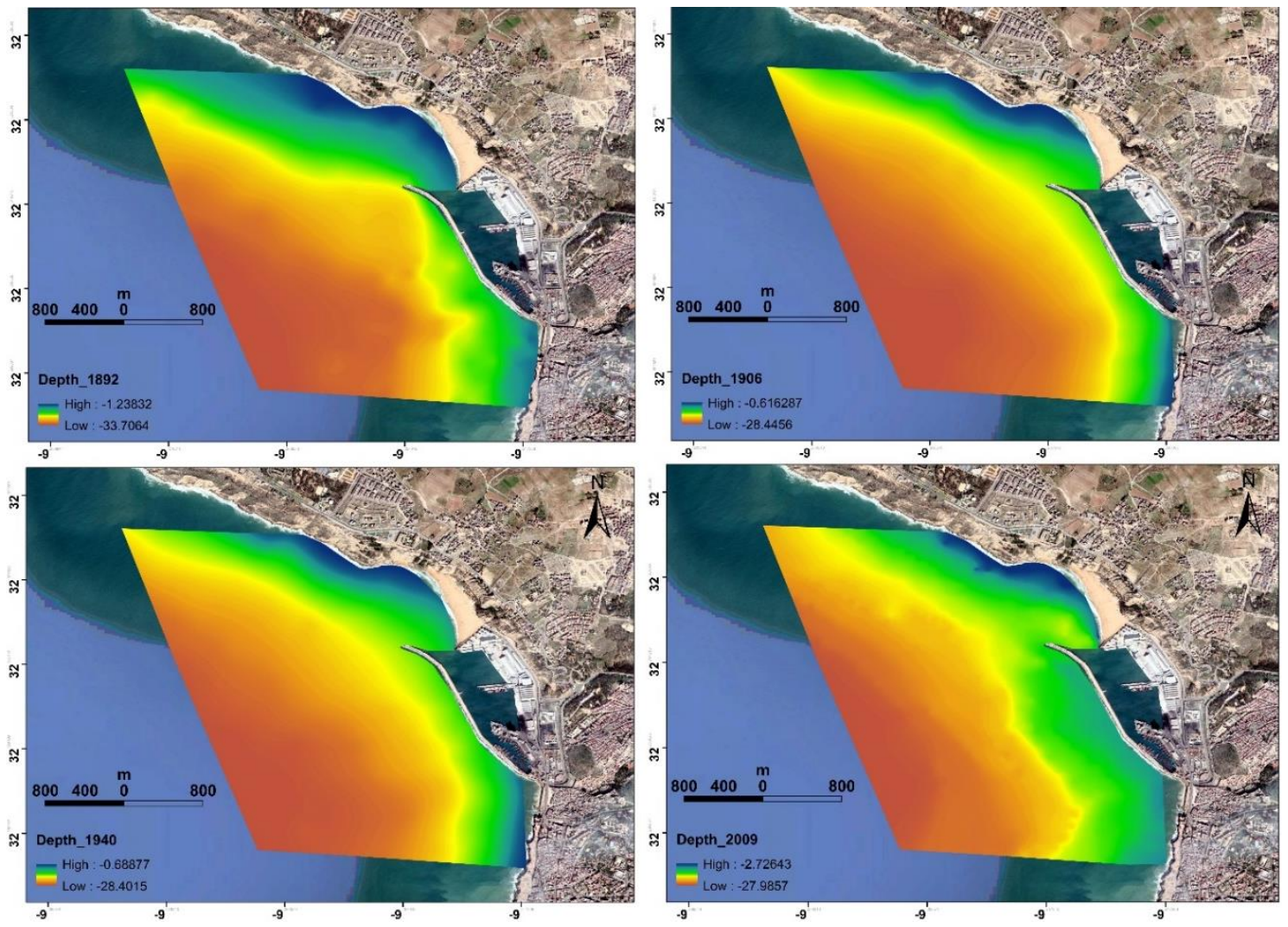

Figure 4. Interpolation maps of the bathymetry of the bay of Safi before, during and after the construction of the port. 
The arithmetical difference between the bathymetry of 1906 and 1940 reveals that accretion continued in the northern part of the bay, but in the central part the rate of demaigrisation had slowed down compared to the previous period. This is because the natural balance of the system was considerably disturbed by the construction of the harbor, which began in 1906. The decrease of the erosion of the latter can be at the origin of the trapping of the sediments transited from north to south. The total volume of sediments deposited, by the coastal transit, during this period was $2910815,62 \mathrm{~m}^{3}$ calculated on a surface of $4521869 \mathrm{~m} 2$ (figure). These sediments are dispersed by the currents feeding the shallows of the bay. Other studies around the world have shown that the construction of a harbor has altered the physical characteristics and hydrodynamic sedimentation process of the bay (Henrico and Bezuidenhout, 2020; Wenyun Guo et al., 2018). While south of the harbor, a comparison of bathymetric
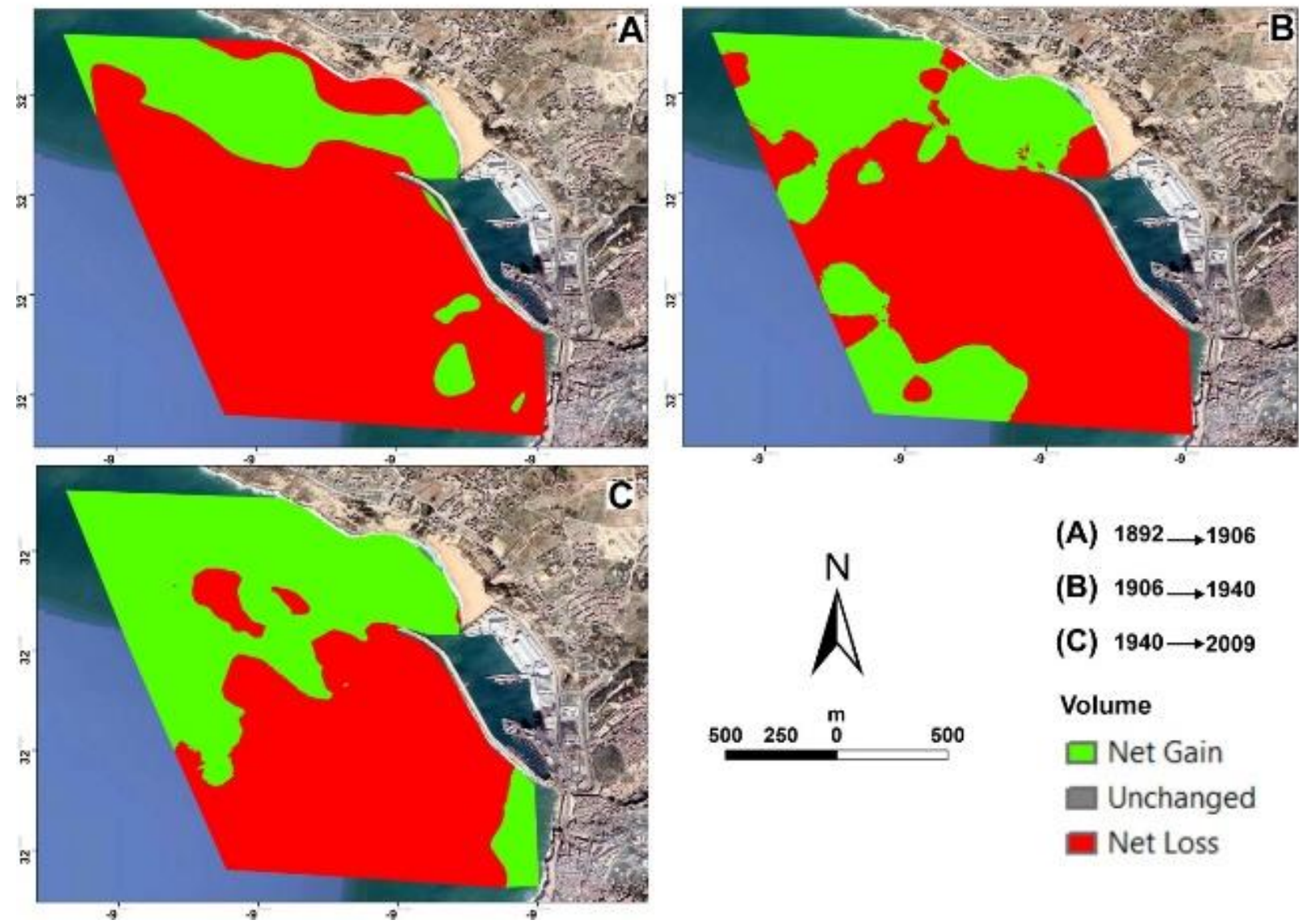

dhe volume lost of $2855941 \mathrm{~m}^{2}$. This period had seen an extension of the port, which trapped the sediments transited from the north to the south and modified the sedimentary volumes as well as the morphology of the small bottoms of the bay. The diachronic study of the coastline of the bay of Safi suggests that there was a net erosion on the southern part of the shoreline after the construction of the port and a progression in its southern part (Minoubi et al., 2018). Many coastal zone developments confirm these results (Albert, 2016; Aouiche et al., 2016; Eddine and Abdellaoui, 2007; Idrissi et al., 2004). Sediment deposition in a harbor is quite common, due to the reduction of incident wave energy and interruption of sediment transport along the coast (Dubois, 2000).

Figure 5. Bathymetric difference maps of Safi Bay during the period 1892-2009

Comparison of the two bathymetric surveys 1940-2009 clearly shows that the morphological evolution of the bay was marked by little change compared to the previous period. There is very limited accretion in the north and erosion in the south, while the rest of the bay is marked by slight stability. The volume of sediment deposited in the northern part of the harbor was $7367762.049 \mathrm{~m}^{3}$ calculated on an area of $3855258 \mathrm{~m}^{2}$. In the southern part, the volume lost was $5287569.744 \mathrm{~m}^{3}$ over an area of $3484227 \mathrm{~m}^{2}$. This evolution indicates that the completion of the harbor extension stabilizes the rate of change in the bay, the sediment dynamics are carried out only under the action of a new hydrodynamic system generated after the construction of the harbor. The sediments are reworked only by the currents of the fonts causing small morphodynamical changes in the bay (Zakarya, 1994). 

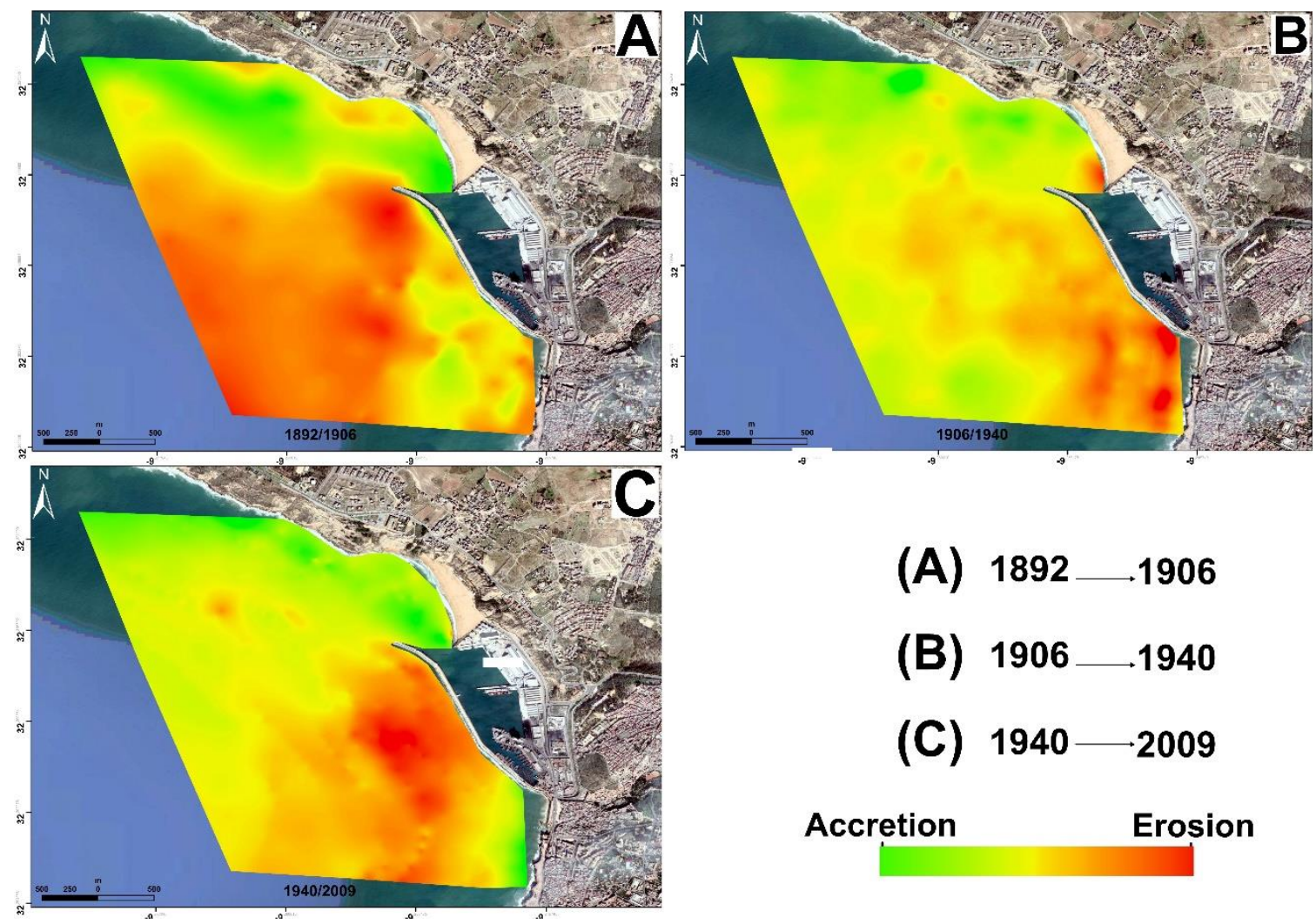

Accretion

Erosion

Figure 6. Erosion-accumulation patterns in the bay of Safi for the period from 1892-2009.

\section{CONCLUSION}

The analysis of sedimentary bathymetric variations in the Bay of Safi for the period from 1892 to 2009 (116 years) has been assessed. This analysis indicates that the evolution of the seabed in the bay seems to be variable between 1892 and 1940, especially before the final extension of the port. However, the expansion of the port affected the coastline and the nearby seabed. These developments have modified the speed and direction of the tidal currents around the harbor favoring local phenomena, which caused changes in sedimentary facies.

Moreover, the superposition of bathymetric surveys showed that the erosion was almost localized in the central part of the bay during the period 1892-1906, except in the northern part, which experienced an uplift. These changes are mainly related to the hydrodynamic forcing that acts on the environment. The forcing factors such as currents and waves were modified as the port expanded (1906-1940 period). The latter traps the sediments transited from the north and which are dispersed by the tidal currents to feed the shallows. During this period, the erosion rates decreased and the bay experienced a slight lowering in its central part. The last period (1940-2009), coinciding with the end of the development, shows that the erosion remains limited just next to the port.

\section{REFERENCES}

Albert, S., 2016. Impacts des aménagements sur le littoral des Mathes. Pays Royannais Ennvironnement 36.

Aouiche, I., Daoudi, L., Anthony, E.J., Sedrati, M., Ziane, E.,
Harti, A., Dussouillez, P., 2016. Anthropogenic effects on shoreface and shoreline changes: Input from a multi-method analysis, Agadir Bay, Morocco. Geomorphology 254, 16-31. https://doi.org/10.1016/j.geomorph.2015.11.013

Charrouf, 1991. Problèmes d'ensablement des ports marocains sur la façade atlantique. Leur impact sédimentologique sur le littoral. La Houille Blanche 77, 49-71. https://doi.org/10.1051/lhb/1991004

Curtarelli, M., Leão, J., Ogashawara, I., Lorenzzetti, J., Stech, J., 2015. Assessment of Spatial Interpolation Methods to Map the Bathymetry of an Amazonian Hydroelectric Reservoir to Aid in Decision Making for Water Management. ISPRS Int. J. GeoInformation 4, 220-235. https://doi.org/10.3390/ijgi4010220

Dubois, J.-M.M., 2000. Komar, Paul D., 1998. Beach Processes and Sedimentation. 2e édition, Prentice Hall, Upper Saddle River (New Jersey), x + 544 p., 383 fig., 16 tabl., 18 x 24 cm, 100,95 \$. ISBN 0-13-754938-5. Géographie Phys. Quat. 54, 127. https://doi.org/10.7202/004810ar

Eddine, J., Abdellaoui, E.L., 2007. De L 'Évolution Du Trait De Côte De La Baie De Tanger ( Maroc ).

El Khalidi, K., Faculty, K., Unive, D., Universit, B.Z., Doukkali, C., 2012. Land use evolution of the coast blanc cap to cantin cap ( moroccan atlantic coast ): Cartography by aerial photography ...

Flor-Blanco, G., Pando, L., Morales, J.A., Flor, G., 2015. Evolution of beach-dune fields systems following the construction of jetties in estuarine mouths (Cantabrian coast, 
NW Spain). Environ. Earth Sci. 73, 1317-1330. https://doi.org/10.1007/s12665-014-3485-1

Henrico, I., Bezuidenhout, J., 2020. Determining the change in the bathymetry of Saldanha Bay due to the harbour construction in the seventies. South African J. Geomatics 9, 236-249.

Idrissi, M., Hourimeche, A., Rey, V., Chagdali, M., 2004. Impact des installations côtières sur l'évolution du littoral de Mohammedia (Maroc) 789796.https://doi.org/10.5150/jngcgc.2004.086-i

J, V., 1951. Etude sédimentologique de la rade de Safi. Bull. Sci. Com. Local Océan.Etude Côtes Maroc, 39-43.

Martin Seeliger. Helmut Brückner, M.B.S.F.M.K.F.P., 2012. The Harbour of Pergamum - Coastal Evolution of the Bay of Elaia (NW Turkey). J. Topoi, Proc. Int. Conf. Held Berlin 3, 107-112.

Minoubi, A., Elkhalidi, K., Chaibi, M., 2018. Impact des ouvrages portuaires sur l' évolution du trait de côte de la baie de Safi ( littoral atlantique-Maroc ) Résumé 18-35

Paskoff, R. et F.V., 1998. La crise des plages: pénurie de sédiments. Mappemonde 52, 11-16.

Samat, O., Les, S.U.R., Microtidales, P., 2007. ENROCHEMENT.

Stanica, A., Dan, S., Ungureanu, V.G., 2007. Coastal changes at the Sulina mouth of the Danube River as a result of human activities. Mar. Pollut. Bull. 55, 555-563. https://doi.org/10.1016/j.marpolbul.2007.09.015

Wenyun Guo, Xiao Hua Wang, Pingxing Ding, Jianzhong Ge, D.S., 2018. A system shift in tidal choking due to the construction of Yangshan Harbour, Shanghai, China. Estuar. Coast. Shelf Sci. 206, 49-60.

Zakarya, E., 1994. La houle et son impact sur le littoral atlantique Marocain., approche par modélisation. Univ. Paris IV 204. 